\title{
IDEIA, SER OBJETIVO E REALIDADE OBJETIVA NAS “MEDITAÇÕES” DE DESCARTES
}

\author{
Raul Landim Filho* \\ raullandim@uol.com.br
}

RESUMO $O$ objetivo deste artigo é responder à questão: a teoria cartesiana das ideias é realista direta ou representacionalista? Para responder a essa questão, analiso as noções de ideia, ser objetivo, realidade objetiva e essência nas "Meditações" de Descartes. Eu procuro mostrar que do ponto de vista da apreensão das essências das coisas externas, Descartes é um realista direto. Mas como algumas provas da existência são inferenciais, eu mostro também que deste ponto de vista a teoria cartesiana é representacionalista.

Palavras-chave Realismo direto, representacionalismo, ideia, ser objetivo, realidade objetiva, essência.

ABSTRACT My aim in this article is to answer the question: is the Cartesian Theory of Ideas a direct realist or a representationalist theory? To answer this question, I analyze the notions of idea, objective being, objective reality and essence in Descartes's "Meditations". I show that, from the point of view of the apprehension of the essences of external things, Descartes is a direct realist. However, since some proofs of the existence are inferential, I also show that, from this standpoint, the Cartesian theory is a representationalist theory.

Keywords Direct Realism, Representationalism, Idea, Objective Being, Objective Reality, Essence.

* Pesquisador $1 \mathrm{~A}$ do CNPq e Professor do Programa de Pós-Graduação Lógica e Metafísica do IFCS/UFRJ. Artigo recebido em 17/09/2013 e aprovado em 08/10/2013. 
A análise da teoria das ideias cartesiana tem várias portas de entrada: as medievais como, por exemplo, a noção de ser objetivo, introduzida por Scotus e tematizada pelo seu discípulo Alnwick, a de conceito formal e de conceito objetivo, difundida por Suarez, e ainda mesmo as análises modernas como a noção de inexistência intencional ou de objetividade imanente de Brentano que, inspirada em concepções escolásticas, teve enorme influência na filosofia do século XX.

Neste artigo, não pretendemos realizar um estudo histórico sobre as influências medievais na teoria cartesiana das ideias nem sobre o impacto e a relevância dela nos sistemas pós-cartesianos. É fato que Descartes retomou e reinterpretou noções escolásticas e por isso mesmo foi fortemente influenciado por elas. Dessa maneira, sua teoria das ideias não só contribuiu para uma valoração retrospectiva de certas teses da filosofia medieval, como também trouxe à tona questões que se tornaram determinantes para a filosofia moderna. Refiro-me, em particular, à questão do 'acesso' ou da percepção do mundo exterior. Quais seriam os objetos imediatos do conhecimento: seriam as coisas 'fora' da mente ou as próprias ideias, no sentido cartesiano do termo 'ideia'? O objeto imediato do intelecto seria o conteúdo da ideia, aquilo que a ideia exibe na mente? Ou seria a própria coisa, isto é, a coisa tornada objeto para o cognoscente em razão das operações do intelecto? O Realismo Direto e o Representacionalismo ${ }^{1}$ são interpretações que dão respostas alternativas a essas questões.

\section{Em uma carta Descartes escreve: ${ }^{2}$}

Pois estando certo que eu não posso ter conhecimento algum do que está fora de mim senão através das ideias dessas coisas que tive em mim, eu me preservo [je me garde bien] de relacionar meus juízos imediatamente às coisas e de nada lhes atribuir de positivo que não perceba anteriormente em suas ideias $[\ldots] .^{3}$

1 São diversos os significados que diferentes autores dão aos termos 'Realismo Direto' e 'Representacionalismo'. De uma maneira genérica, para o Realismo Direto as operações envolvidas no ato de apreensão ou de percepção intelectual têm como termo a coisa mesma, que, por ser o termo dessas operações, é tornada, graças a elas, um objeto para o intelecto. Sob este aspecto, a apreensão de objetos seria uma relação diádica cujos termos são [i] as operações do cognoscente e [ii] a coisa mesma, apreendida ou percebida como objeto. Diferentemente do Realismo Direto, o Representacionalismo supõe uma relação triádica entre [i] as operações do cognoscente, [ii] o objeto mental, constituído por essas operações, e [iii] a coisa extramental, apreendida ou percebida pela mediação do objeto mental. Vide Michon (2007, p. 154, nota 40); Hoffman (2002, p. 163).

2 Em geral, citaremos a obra de Descartes na edição standard de C. Adam e P. Tannery, 1964-1974. Ao citar os textos de Descartes, usaremos a seguinte abreviação: AT, seguida do número do volume, do título da obra, da página e algumas vezes da linha.

3 AT, III, Carta a Gibieuf de 19 de janeiro de 1642, p. 474. 
À primeira vista este texto parece sustentar a interpretação representacionalista: mediante as ideias seriam apreendidas as coisas 'fora' da mente. No entanto, as ideias não são consideradas como objetos imediatamente cognoscíveis, mas como meios: se algo é apreendido 'fora' de mim, é apreendido mediante uma ideia. Dessa maneira, o texto não exclui nem corrobora a interpretação Representacionalista ou a Realista Direta. Ele apenas reitera uma tese inquestionável para o cartesianismo: as ideias, imanentes ao pensamento ( $\mathrm{em} \mathrm{mim}$ ), são ideias de coisas. ${ }^{4}$ Mas a questão da natureza das coisas das quais se têm ideias não fica esclarecida: elas seriam entes objetivos que existem intencionalmente no pensamento e permitem o acesso mediato às coisas 'fora' da mente ou seriam as coisas mesmas, visadas e apreendidas pelo pensamento, que podem existir independentemente da mente?

Ao formular uma objeção a Descartes, Caterus, autor das Primeiras Objeções, explica, segundo sua perspectiva, o significado do termo "ideia" e o de "ser objetivo": "O que é ser uma ideia? É a própria coisa pensada enquanto ela existe (est) objetivamente no intelecto. Mas o que é ser objetivamente no intelecto? Apreendi há muito tempo: é terminar o próprio ato do intelecto à maneira de um objeto" (AT, VII, "Primae Objectiones", p. 92; AT, IX-1 "Premières Objections", p. 74).

$\mathrm{Na}$ sua resposta, Descartes afirma que não concorda com o significado dado por Caterus à noção de "ser objetivo": "E lá ser objetivamente no intelecto não significará terminar sua operação à maneira de um objeto, mas ser no intelecto à maneira que os seus objetos têm o costume de aí existir (ser) [...]" (AT, VII, "Primae Responsiones", p. 102; AT, IX-1, "Premières Réponses", p. 82).

Caterus parece assumir uma posição característica de uma forma de Realismo Direto. Descartes discorda de Caterus. Estará discordando do Realismo Direto? Esclarecer as noções ser objetivo e realidade objetiva em Descartes e, em razão disso, responder às questões acima enunciadas, é o objetivo desse artigo. ${ }^{5}$

4 Ver AT, VII, "Meditationes de Prima Philosophia", pp. 35, 37, 41, 42; AT, IX-1, "Les Méditations Métaphysiques", pp. 28, 29, 31, 32; "Principia Philosophiae", I, * 48; AT, III, Carta a Mersenne, julho de 1641, pp. 392-393.

5 Note-se que intérpretes recentes de Descartes continuam a divergir sobre as respostas a serem dadas a essas questões. As divergências se manifestam na defesa ou na rejeição da interpretação Realista Direta ou Representacionalista. Por exemplo, V. Chappell (1986), P. Hoffman (2002) e M. Ayers (1998) defendem uma interpretação representacionalista. S. Nadler (1998), A. Kermmerling (2004), D. Brown (2007) e OngVan-Kung (2012), assumem a interpretação Realista Direta como a mais correta em relação à teoria das ideias cartesiana. D. Clemenson (2007) apresenta uma interpretação sui generis, próxima ao Realismo Direto. Essas divergências de interpretação têm origem seja na ambiguidade da teoria cartesiana, seja 
Respondendo a duas objeções ao "Discurso do método", Descartes, no Prefácio à edição latina das "Meditações", escreve:

Mas, eu respondo que nesta palavra 'ideia' há um equívoco, pois ou ela pode ser tomada materialmente por uma operação do meu intelecto e neste sentido não se pode dizer que ela seja mais perfeita do que eu, ou ela pode ser tomada objetivamente pela coisa que é representada por esta operação, coisa que embora não se suponha que ela exista fora do meu intelecto, pode, entretanto, ser mais perfeita do que eu, em razão da sua essência. ${ }^{6}$ (AT, VII, "Meditationes", p. 8)

Ao pretender eliminar a ambiguidade do termo 'ideia', Descartes parece ter engendrado uma nova dificuldade: segundo o texto acima citado, ou bem a noção de ideia é um ato uno ${ }^{7}$ decomposto em duas relações ou em dois aspectos complementares ou bem "ideia" teria dois sentidos distintos: a operação representativa do intelecto e a coisa pensada. Note-se que o termo "coisa pensada" é ambíguo. Ele tanto pode significar a coisa fora da mente, visada e percebida pelo intelecto, como pode significar a coisa no intelecto (ser objetivo). ${ }^{8}$

$\mathrm{Na}$ primeira interpretação do termo 'ideia', o ato representativo do intelecto pode ser analisado em um duplo aspecto: considerado materialmente, ele é analisado em sua relação com o intelecto; considerado objetivamente, ele significa a coisa exibida pela ideia. É a operação do intelecto ou a realização do ato que é representativo, pois ele exibe uma coisa que, dessa maneira, se torna uma coisa inteligida ou pensada, isto é, um objeto para o intelecto. A coisa exibida pela ideia não precisaria existir 'fora' do intelecto para ser representada como coisa. $O$ que a ideia exibe como coisa, quer exista quer

no célebre debate entre Arnauld (atualmente interpretado ora como um Realista Direto, ora como um Representacionalista) e Malebranche.

6 Ver também AT, VII, "Quartae Responsiones”, p. 232; AT, IX-1, Quatrièmes Réponses, p. 180. Nesse texto a expressão 'objetivamente', que ocorre no Prefácio à edição latina, é substituída pela expressão 'formalmente': A. Kemmerling, no entanto, distingue o sentido de ideia considerada objetivamente do sentido de ideia considerada formalmente: "[...] Descartes introduces another distinction, namely between an idea taken materially and an idea taken formally. An idea is being taken in the formal sense when it is "referred to something else", when it is taken to represent "something real and positive". Ver A. Kemmerling, 2004, pp. 43-64, em especial, p. 54. Não me parece correta esta afirmação de Kemmerling.

7 Ver AT, III, Carta a Mersenne, 28 de janeiro de 1641, p. 295. Ver também Arnauld, 1986, c. 5, Definição 6, p. 44-45: "Eu digo que eu tomava como a mesma coisa a percepção e a ideia. É necessário observar que esta coisa, embora única, tem duas relações, uma com a alma que ela modifica, outra, à coisa percebida enquanto ela está objetivamente na alma [...] não são duas entidades diferentes, mas uma mesma modificação de nossa alma, que envolve essencialmente essas duas relações."

8 Vide a caracterização de ideia numa nota da tradução latina, autorizada por Descartes, do texto original francês do "Discurso do método" (AT, VI, "Dissertatio de Methodo", p. 559): "[...] o nome de Ideia é tomado em geral por toda coisa pensada, enquanto ela tem somente algum ser objetivo no intelecto". Como se observa, essa caracterização de ideia não é ambígua. 
não, pode ter uma essência, num sentido minimalista de essência: não é um ente fictício nem um ente de razão.

Na segunda interpretação, 'ideia' teria um duplo significado: poderia ser considerada ou bem como a operação representativa do intelecto ou bem como a coisa representada. ${ }^{9}$ Aparentemente, essa segunda interpretação em pouco difere da primeira. No entanto, por distinguir dois significados de ideia, ela traz à tona a questão do estatuto da natureza da coisa pensada. Ela seria uma entidade que independe da operação representativa? Obviamente, não há coisa pensada que não seja pensada pelo intelecto; portanto, que não seja exibida pelo pensamento. Mas o objeto do pensamento é a coisa no pensamento ou é a coisa mesma visada pelo pensamento?

A segunda interpretação suscita de imediato uma série de questões que alimentaram e ainda alimentam o debate entre as interpretações realistas diretas e representacionalistas: qual seria a relação da ideia, enquanto coisa pensada, com a ideia considerada como operação do intelecto? Qual seria a relação da coisa pensada com a coisa, seja esta uma mera essência ou uma coisa existente? A coisa pensada, a coisa no pensamento, é um tertium quid, um intermediário entre a operação representativa e a própria coisa ou seria a própria coisa, apreendida pela operação representativa?

$\mathrm{Na} 3^{\mathrm{a}}$ Meditação, após afirmar que todos os modos do pensamento envolvem ideias e que ideias são pensamentos de coisas ${ }^{10}$ o que realça a intencionalidade do pensamento, Descartes caracteriza as ideias "como imagens de coisas" (AT, VII, "Meditationes", p. 37; AT, IX-1, "Méditations", p. 29), o que sublinha, desta vez, a função representativa das ideias.

Esta última caracterização suscita uma pergunta: é a operação ou a coisa no pensamento que exerce a função representativa? Se a ideia é um ato único, decomposta em dois aspectos complementares, então seria plausível afirmar que a operação do intelecto exerce a função representativa, pois, no seu termo ela exibe uma coisa que, dessa maneira, se torna um objeto para o intelecto. É o ato que intelige que é representativo e não a coisa inteligida. Sob este aspecto, representar significa exibir ou apresentar uma coisa-objeto para o intelecto. Assim, ao invés de ser considerada como uma espécie de um quadro pictórico ou de um quadro mudo, a ideia é "como imagens de coisas" porque num único ato visa e exibe coisas para o intelecto.

9 Ver M. Ayers,1998, p. 1067.

10 AT, VII, "Meditationes", p. 35; AT, IX-1, "Méditations", p. 28. Ver também AT, III, Carta a Mersenne de julho de 1641, pp. 392-393. 
Se, no entanto, a ideia tem dois significados distintos, operação do intelecto e coisa no pensamento, seria plausível, embora não necessário, considerar a coisa pensada no intelecto como uma imagem inteligível ou um substituto no intelecto da própria coisa. A essa hipótese, poderia ser acrescentado outro passo decisivo: a coisa no pensamento poderia ser considerada o objeto imediato ${ }^{11}$ de cada um dos nossos pensamentos, uma espécie de intermediário entre a operação do intelecto e a coisa mesma. A interpretação Representacionalista estaria, nesse caso, sendo assumida.

$\mathrm{Na} 3^{\mathrm{a}}$ Meditação, Descartes dará uma resposta provisória às questões acima formuladas. A resposta é provisória porque contextual: é num quadro cético e solipsista que na $3^{a}$ Meditação é analisada a noção de ideia. O que nesse contexto pode ser dito sobre as coisas das quais temos ideias? Já que a realidade e a existência de coisas 'fora' ou independentes da mente estão postas em questão pelas dúvidas formuladas na $1^{\mathrm{a}}$ Meditação, como explicar $o$ que são as coisas das quais temos ideias? A resposta a esta pergunta tem que levar em conta o contexto em que ela é formulada. A indubitabilidade do Cogito, provada na $2^{\text {a }}$ Meditação, se propaga aos atos cogitativos ou aos modos do pensamento (AT, VII, Objectiones Tertiae, Objectio II, Responsio; AT, IX1, Objection II, Réponse). Dentre os diversos modos de pensar, a ideia é um modo prioritário (AT, VII, "Meditationes", p. 37; AT, IX-1, "Méditations", p. 29), pois todos os outros modos, como, por exemplo, as ações da vontade, envolvem uma ideia. Portanto, é indubitável e verdadeiro que penso em coisas ou que tenho ideias de coisas, mas é dubitável que as coisas das quais tenho ideias independam do pensamento. Daí se segue que as coisas das quais temos ideias têm que ser provisoriamente consideradas como coisas no pensamento, pois a existência delas 'fora' do pensamento é dubitável.

Nesse contexto cético e solipsista, Descartes explicita a caracterização de ideia formulada no Prefácio à edição latina das "Meditações". Consideradas do ponto de vista da sua realidade formal, as ideias são seres reais e positivos, modos do pensamento e todas parecem proceder da res cogitans da mesma maneira: elas são operações da mente e, enquanto tais, elas não se diferenciam. Mas, diz o texto latino "mas enquanto uma representa uma coisa, outra, outra coisa, é evidente que essas mesmas ideias são bastante diferentes umas das outras." (AT, VII, "Meditationes", p. 40). A tradução francesa desse texto acrescenta a palavra "imagem": as ideias representam coisas porque são imagens de coisas: "[...] mas, considerando-as (as ideias) como imagens,

11 Ver AT, VII, Objectiones Tertiae, Objectio V, Responsio; AT. IX-1, Troisièmes Objections, Objectio V, Réponse. Nesse texto, Descartes afirma que ideia é tudo aquilo que é imediatamente percebido pela mente. 
dentre as quais algumas representam uma coisa e as outras uma outra, é evidente que elas são bastante diferentes entre si" (Descartes, 1962, p. 143, grifo meu). Mas por que seriam imagens? ${ }^{12}$ Em razão de exibirem coisas no pensamento?

Analisada do ponto de vista do seu conteúdo ou ideato, a noção de ideia possibilita a introdução de duas noções decisivas: a noção de realidade objetiva e a de ser objetivo. Como já foi dito, as coisas exibidas pelas ideias permitem diferenciar as ideias entre si. Isso parece ser uma razão para afirmar que as coisas que no pensamento permitem diferenciar as ideias não são "um puro nada", isto é, são entes que estão ou existem no pensamento como objetos. Daí serem denominados entes objetivos.

Se as ideias se distinguem entre si pelos diferentes objetos que exibem e por isso eles são considerados entes objetivos, então entes de razão também poderiam ser considerados entes objetivos, na medida em que são objetos de ideias. É o que afirma, por exemplo, Eustachio de S. Paulo, ${ }^{13}$ escolástico que Descartes apreciou, ${ }^{14}$ que identificou esse objectivum com objeto do intelecto. ${ }^{15}$ Nesse caso, ser objetivo significa apenas ser objeto do intelecto, ou terminar o ato do intelecto, como escreve Caietano. ${ }^{16}$ Dessa maneira, entes de razão seriam os entes objetivos que não têm ser além do pensamento. ${ }^{17}$ Mas, entes de razão devem ser considerados como 'um puro nada', pois fabricados pela razão, não podem ter realidade formal ou atual.

A análise imanente da ideia no contexto cético da $3^{\mathrm{a}}$ Meditação não impede que os objetos das ideias sejam denominados entes objetivos, isto é, objetos que estão no intelecto. Mas se a diferença entre as ideias se apoia

12 Um texto crucial da 3a Meditação parece indicar que as ideias são uma espécie de quadro: "De sorte que a luz natural me faz conhecer evidentemente que as ideias estão em mim como quadros ou imagens [veluti quasdam imagines] [...]" Descartes, 1962, "Meditações", p. 143; AT, IX-1, "Méditations", p. 31; AT, VII, "Meditationes", p. 42. A propósito desse texto, ver o comentário clássico de M. Gueroult (1953, v. I), sobre o Princípio de Causalidade e o de Conformidade (Correspondência) entre a ideia e o seu ideato, pp. 194-203.

13 Eustachio à Sancto Paulo,1609, Quarta Pars, Quaestio III, pp. 17-20.

14 Ver as seguintes cartas endereçadas por Descartes a Mersenne em AT, III: [a] 11 de novembro 1640, pp. 231-232; [b] dezembro 1640, p. 259; [c] 22 de dezembro 1641, p. 470.

15 Eustachio, 1609, Quaestio III, p. 17: "Esse objective in intellectu nihil aliud esse quam actu objici intellctui cognocenti sive illud quod objicitur cognoscendum vere sit in intellectu aut extra intellectum sive vere non sit."

16 Ver o comentário de Caietano ao "De Ente et Essentia" de Tomás de Aquino. Caietano reinterpreta o sentido do termo "ser objetivo" de Scotus para adaptá-lo a gnosiologia tomista: "Esse in intellectu objective est terminare actum intellectus". Thomae de Vio Caietani,1907, c. IV, q. 7. Ver também a propósito da noção de ser objetivo, a crítica de Caietano a Scotus no seu comentário da "Summae Theologiae", de Tomás de Aquino, t. Quartus, Pars Prima, q. 14, a. 6, comentário, itens XI-XII. Segundo Caietano, ser objetivo em Scotus é um ser real secundum quid.

17 Eustachio 1609. Quaestio III, p. 18: "At vero quaedam sunt quae nullum habent aliud esse praeter esse objectivum seu esse cognitum ab intellectu, et haec dicuntur entia rationis [...]". 
exclusivamente no fato de que as ideias exibem no intelecto diferentes objetos, não se pode extrair dessa afirmação que os objetos das ideias não são 'um puro nada', pois entes de razão são entes objetivos e são um 'puro nada'.

De fato, a tese cartesiana na $3^{\mathrm{a}}$ Meditação não é a de que as ideias são diferentes somente em razão dos objetos que exibem, mas elas se diferenciam em razão dos graus de perfeição que os seus objetos têm no pensamento. Descartes constata, como se fosse um fato, que a ideia de substância tem maior grau de perfeição do que as ideias de modo e a ideia de substância infinita maior grau de perfeição do que a ideia de substância finita.

Mas, considerando-as (as ideias) como imagens, dentre as quais algumas representam uma coisa e as outras uma outra, é evidente que elas são bastante diferentes entre si. Pois, com efeito, (Nam proculdubio, na versão latina) aquelas que me representam substâncias são, sem dúvida, algo mais e contêm em si (por assim falar) mais realidade objetiva, isto é, participam por representação [acréscimo da versão francesa] num maior número de graus de ser ou de perfeição do que aquelas que representam modos ou acidentes. (Descartes, 1962, "Meditações", p. 142; AT, VII, "Meditationes", p. 40; AT, IX-1, "Méditations", p. 32; grifo meu)

Nem sempre Descartes distingue a noção de realidade objetiva da de ser objetivo. A versão francesa da Exposição Geométrica (AT, IX-1, Séconde Réponses, def. III) define Realidade Objetiva como a entidade ou o ser da coisa representada pela ideia, o que permitiria assimilar as noções de realidade objetiva e de ser objetivo. O texto latino é mais conciso: realidade objetiva é caracterizada como a entidade da coisa representada pela ideia, o que sugere a distinção entre ser objetivo de realidade objetiva (AT, VII, Secundae Responsiones, def. III).

O texto cartesiano não exclui a distinção entre essas duas noções: a noção de ser objetivo referir-se-ia ao objeto da ideia que está ou existe no pensamento; a noção de realidade objetiva significaria o grau de perfeição ou de realidade do ser objetivo. Assim, em uma interpretação minimalista, "ser objetivo" significaria tão somente o objeto do intelecto exibido ou representado pela ideia, pois sua noção não envolve nem é dependente da noção de realidade objetiva. Certa tradição medieval considerou ser objetivo como um ser de razão, uma denominação extrínseca à realidade da coisa. Ser objeto do intelecto não implicaria ter uma realidade ou uma perfeição no intelecto. Quais seriam, então, as razões de Descartes para afirmar que certos objetos do intelecto têm graus de perfeição?

Na Exposição Geométrica (AT, VII, Secundae Responsiones, Axioma 6; AT, IX-1, Secondes Réponses, Axioma 6), Descartes sugere uma resposta a essa pergunta: parece evidente que a substância infinita tem um grau de perfeição 
maior do que a substância finita e as substâncias graus maiores do que os seus modos. Essa tese, que remonta à ontologia aristotélica, não suscita, ao menos no contexto da recepção medieval do aristotelismo, objeções relevantes. Mas, Descartes extrai dela uma consequência significativa: por isso ('Ideoque' no texto latino; 'C'est pourquoi' segundo a versão francesa) a ideia de substância infinita tem um grau maior de perfeição do que a ideia de substância finita e esta um grau maior do que a ideia de modo. Segundo o Axioma 6, o grau de realidade ou de perfeição dos seres objetivos seria derivado do grau de realidade dos entes atuais ou formais (entes em si).

Este argumento suscita objeções óbvias: ele não pode ser válido no contexto cético da $3^{\mathrm{a}}$ Meditação, onde a dúvida sobre o mundo externo e a dúvida metafísica ainda não foram eliminadas. No entanto, do ponto de vista do sistema completo das "Meditações", quando as dúvidas acima citadas já tiverem sido eliminadas, segundo uma teoria causal das ideias, o argumento poderia ser considerado plausível à condição que tenha sido demonstrado que os seres objetivos têm realidade e, por conseguinte, graus de perfeição. De fato, o argumento apresentado pelo Axioma 6 da Exposição Geométrica hierarquiza graus de perfeição, o que pressupõe que seja correta a afirmação de que os seres objetivos, como os entes que têm uma realidade atual ou formal, tenham também realidade ou perfeição no pensamento.

Nas Respostas às Primeiras Objeções às "Meditações", formuladas por Caterus (AT, VII, pp. 101-121; AT, IX-1, pp. 81-95), Descartes procura esclarecer o significado e a função do termo ser objetivo e justificar a tese de que as ideias contêm uma realidade objetiva. $O$ contexto desse debate não é o mesmo da $3^{\text {a }}$ Meditação. A dúvida sobre a existência do mundo exterior não é levada em consideração. Questiona-se, inicialmente, se as ideias são submetidas ao princípio de causalidade. Se elas têm uma realidade objetiva, então, em princípio, seria legítima a pergunta sobre a causa das ideias.

A estratégia de Caterus é a de assumir teses cartesianas e mostrar, em seguida, que estas teses conduzem a conclusões que Descartes não poderia aceitar, pois se as aceitasse, a coerência do seu sistema estaria comprometida. O ponto de partida do debate é a definição de ideia, atribuída por Caterus a Descartes e que Descartes assume como sua, embora, ao que parece, jamais a tenha explicitamente formulado (AT, VII, Primae Objectiones, p. 92, 1.13-14; AT, IX-1, Premières Objections, p. 74). A ideia, escreve Caterus, é a coisa pensada enquanto existe (ou está) objetivamente no intelecto. ${ }^{18}$ Ser est terminare actum intellectus.”. Thomae de Vio Caietani,1907, c. IV, q. 7. 
objetivamente no intelecto é terminar como objeto o próprio ato do intelecto. ${ }^{19}$ Assim, ser objetivo é a própria coisa enquanto objeto do intelecto. Caterus formula, dessa maneira, uma versão simples e talvez convincente do Realismo Direto: a operação representativa ou perceptiva do intelecto termina ao apreender uma coisa, que se torna, graças a essa apreensão, um objeto para o pensamento. A noção de ser objetivo exprimiria apenas a intencionalidade do pensamento. Quando penso no sol, não penso na ideia do sol, mas no próprio sol, que se tornou objeto para o meu pensamento, graças à operação representativa. Dessa maneira, a representação seria uma relação diádica: de um lado as operações representativas do sujeito cognoscente, de outro, a própria coisa. Obviamente, a coisa pensada pode ser pensada sem que exista atualmente ou formalmente.

O ser objetivo é uma relação extrínseca à própria coisa, explica Caterus. Nada ocorre à coisa pelo fato dela ser pensada. Assim, ser visto não altera a realidade daquilo que é visto, ser pensado não modifica a coisa que é pensada, embora seja uma modificação acidental do sujeito que pensa. Pode-se, portanto, investigar a causa das coisas ou do sujeito pensante que tem a faculdade de apreender as coisas, mas não tem sentido investigar as causas do ser objetivo, que é uma mera denominação, conclui Caterus, se opondo, dessa maneira, à tese cartesiana.

Além disso, se o termo "nada" é usado para designar as coisas que não têm ser atual ou formal, ser objetivo é um puro nada, como são os entes de razão, na medida em que está no pensamento apenas como uma denominação extrínseca das coisas visadas ou percebidas pelo intelecto. No entanto, concede Caterus, se "nada" significa seres fictícios, o ser objetivo não pode ser considerado um mero nada, pois ele é o termo de uma operação real do cognoscente.

Note-se que, segundo Descartes, porque pensamos em coisas, isto é, porque temos ideias de coisas, somos imediatamente conscientes de nossos pensamentos. Daí se segue que se pode conceber claramente a operação representativa e o seu termo, isto é, o ser objetivo. Sobre este ponto, não há divergência entre Descartes e Caterus. Mas, o que é claramente concebido é a operação representativa que exibe um objeto no termo da sua ação. Conclui, então, Caterus, o ente objetivo pode ser claramente concebido enquanto termo

19 Ser objetivo "[...] est ipsum actum intellectus per modum objecti terminare". AT, VII, Primae Objectiones, p. 92, I. 15-16; AT, IX-1, Premières Objections, p. 74. Note-se que em Descartes, o termo 'objeto' pode significar o que está no intelecto como coisa (pensada) ou a própria coisa fora do intelecto: "Nam quaecumque percipimus tanquam in idearum objectis, ea sunt in ipsis ideis objective." AT, VII, Secundae Responsiones, Definição III, I. 7-10; AT, IX-1, Secondes Réponses, definição III. 
de uma operação representativa, que é um modo do sujeito cognoscente. No entanto, pelo fato de poder ser claramente concebido, não se segue que não depende do pensamento, pois, enquanto denominação extrínseca, o seu ser é de ser pensado, não tendo, portanto, realidade formal ou atual. Assim, o ser objetivo não necessita de causa, pois segundo o escolástico Caterus, só seres atuais são submetidos ao princípio de causalidade.

As objeções de Caterus, que partira de uma caracterização de ideia cartesiana, retomam algumas análises escolásticas, essencialmente tomistas, da noção de ser objetivo. Elas atestam a ambiguidade dessa noção que, desde Scotus e do seu discípulo Alnwick, suscita uma diversidade de interpretações. ${ }^{20}$

A resposta de Descartes a Caterus vai se apoiar em duas considerações complementares e mutuamente imbricadas:

a) ser objetivo é um modo de ser distinto do modo de ser formal ou atual. As ideias, enquanto operações do sujeito cognoscente, têm uma realidade formal, a de ser um modo ou um acidente do sujeito cognoscente. As coisas que existem 'fora' do pensamento são substâncias ou afecções de substâncias ${ }^{21}$ e têm, portanto, uma realidade formal ou atual. O ser objetivo, no entanto, embora seja um ens diminutum, tem outro modo de ser. Assim, mediante a noção de ser objetivo e de realidade objetiva, a ontologia cartesiana reconhece dois modos de ser independentes: uma coisa pode ter um ser formal e não ter um ser objetivo; por sua vez, um ser objetivo pode não ter um correlato formal, embora a sua causa última seja uma realidade formal. ${ }^{22}$

b) o ser objetivo tem certa autonomia ontológica em relação à realidade formal da ideia que o exibe. De um lado, ele é sempre exibido por uma ideia: se $x$ é um ser objetivo, existe uma ideia de $x \cdot{ }^{23}$ Sob este aspecto, o ser objetivo depende da operação representativa. Por outro lado, em certos casos (o das essências matemáticas, por exemplo), ele independe de um correlato formal no mundo para ter uma natureza ou essência. Ele contém, assim, propriedades necessárias que independem quer da realidade formal das ideias, quer da realidade atual das coisas. Analisando as essências matemáticas exibidas pelas ideias, H. Gouhier usa uma expressão que pode caracterizar certos gêneros de entes objetivos: as ideias das essências matemáticas, escreve H. Gouhier,

20 Ver o artigo pioneiro de R. Dalbiez(1929, pp. 464-472) e também os artigos de C. Normore(1986, pp. 223241); N. Wells (1993, pp. 513-535); D. Perler (2001, pp. 203-226); M. Tweedale(2006, pp. 63-79).

21 "Princípios da Filosofia", I, 48; AT, VIII-1, "Principia Philosophiae", I,* 48.

22 Ver o artigo de M. Beyssade,1997, pp. 37-49.

23 Tendo em vista questão das ideias materialmente falsas e das ideias sensíveis, que não serão analisadas neste artigo, não se pode afirmar, sem prévias justificações, que toda ideia exibe um ser objetivo. 
"estão em mim sem serem de mim". ${ }^{24}$ É a autonomia ontológica do ser objetivo face à realidade formal da ideia que torna compreensível a afirmação cartesiana de que o sujeito cognoscente pode conter uma ideia (considerada objetivamente) mais perfeita do que ele.

Ao contrário do que objetara Caterus, ser objetivo, segundo Descartes, não significa terminar como objeto a operação do intelecto, mas existir no intelecto da maneira pela qual objetos têm o hábito de aí existir. O que seria a ideia do sol?

[...] é o próprio sol existindo no intelecto, não formalmente como no céu, mas objetivamente, isto é, da maneira pela qual os objetos têm o costume de aí existir; certamente esse modo de ser é bem menos perfeito do que aquele pelo qual as coisas fora do intelecto existem, mas disso não se segue que sejam um puro nada, como já escrevi antes. (AT, VII, Primae Responsiones, pp. 102-103; AT, IX-1, Premières Réponses, p. 82; grifo meu)

O ser objetivo da ideia do sol pode ser uma denominação extrínseca em relação ao próprio sol, pois nada ocorre ao sol, enquanto existe formalmente no céu, pelo fato de ser pensado. Mas, segundo Descartes, o ser objetivo da ideia do sol não significa apenas que o intelecto percebe ou apreende o sol como objeto, mas significa que próprio sol, visado e apreendido, tem uma existência objetiva no intelecto. Nesse sentido, o ser objetivo do sol não pode ser considerado um puro nada nem ter o nada como origem. É um modo de ser imperfeito, mas enquanto tal, está submetido ao princípio de causalidade.

Afirmar que o ser objetivo, como faz Caterus, não é um ser atual ou formal, não é uma objeção, mas ao contrário, uma corroboração da tese cartesiana sobre o significado de ser objetivo. Afirmar que o ser objetivo pode ser distintamente concebido, como vimos, também não é uma objeção ao cartesianismo. Afirmar, em seguida, que embora seja distintamente concebido, o ser objetivo não precisa de uma explicação causal seria um contrassenso, caso o ser objetivo fosse, como Descartes pretende, uma realidade com graus de perfeição no pensamento.

Se as críticas de Caterus a Descartes expressam as habituais concepções escolásticas sobre a noção de ser objetivo, a resposta de Descartes a Caterus ainda não é conclusiva, pois ela não formula argumentos convincentes que mostrariam que o ser objetivo é no pensamento um ente real que, sob certo aspecto, independe da operação representativa e, em certos casos, da existência do seu correlato formal. 
$\mathrm{Na} 3^{\mathrm{a}}$ Meditação, a primeira prova da existência de Deus, formulada num contexto cético e solipsista, supõe que as ideias exibam no pensamento coisasobjetos que têm graus de realidade ou de perfeição. O texto que introduz a noção de realidade objetiva deixa transparecer que se trata mais da constatação de um fato do que da demonstração ou justificação de uma tese: "[...] aquelas [ideias] que me representam substancias são, sem dúvida, algo mais e contêm em si (por assim falar) mais realidade objetiva [...]" (Descartes, 1962, 3 Meditação, p. 143; AT, VII, "Meditationes", p. 40; AT, IX-1, "Méditations", pp. 31-32; grifo meu).

Na $5^{\text {a }}$ Meditação, a célebre prova ontológica da existência de Deus não recorre nem ao Princípio de Causalidade, usado habitualmente pelos filósofos medievais, nem à noção de realidade objetiva, introduzida na $3^{\text {a }}$ Meditação. Descartes faz economia de noções filosóficas para adequar melhor sua prova à forma argumentativa dos matemáticos. Analisando as ideias de objetos matemáticos, nota-se que dos objetos dessas ideias decorrem necessariamente certas propriedades. Por exemplo, decorre necessariamente do objeto triângulo que a soma dos seus ângulos internos seja igual à de dois retos. A verdade dessa afirmação não depende nem do fato dessa propriedade ter sido apreendida pela operação representativa nem da existência de um triângulo no mundo. ${ }^{25}$ Se da ideia de um objeto decorre necessariamente uma propriedade, essa propriedade é constitutiva desse objeto. ${ }^{26}$ Assim, propriedades que decorrem necessariamente de objetos das ideias pertencem à natureza verdadeira e imutável desse objeto, pois essa natureza não é fabricada pelo pensamento, não depende da vontade do sujeito cognoscente, nem precisa existir no mundo para ser considerada verdadeira e imutável. Elas não são fabricadas pelo intelecto nem adquiridas pelos sentidos; são representadas por ideias inatas. Isso significa que os objetos das ideias inatas têm necessariamente no pensamento uma natureza ou forma ou uma essência determinada e, por

25 "Como, por exemplo, quando imagino um triângulo ainda que talvez não haja em nenhum lugar do mundo, fora do meu pensamento, uma tal figura, e que nunca tenha havido alguma, não deixa, entretanto, de haver uma certa natureza ou forma, ou essência determinada dessa figura, a qual é imutável e eterna, que eu não inventei absolutamente e que não depende de maneira alguma de meu espírito; como parece, pelo fato de que se pode demonstrar diversas propriedades desse triângulo [...] as quais agora, quer queira, quer não, reconheço mui claramente e mui evidentemente estarem nele [...]". Descartes, 1962, 5a Meditação, p. 171; AT, VII, "Meditationes", p. 64; AT, IX-1, "Méditations", p. 51.

26 "Quando dizemos que algum atributo está contido na natureza ou no conceito de uma coisa, é o mesmo que se disséssemos que tal atributo é verdadeiramente dessa coisa e que se pode assegurar que se encontra nela". Descartes, 1962, Segundas Respostas, def. IX; AT, VII, Secundae Responsiones, def. IX; AT, IX-1, Sécondes Réponses, def. IX. Ver também AT VII, Primae Responsiones, p. 115: "Aquilo que clara e distintamente inteligimos pertencer a uma verdadeira e imutável natureza ou essência ou forma de alguma coisa, isto pode ser verdadeiramente afirmado sobre aquela coisa" e AT, IX-1, Premières Réponses, p. 91. Ver também AT, VII, Secundae Responsiones, p. 150 e AT, IX-1, Secondes Réponses, p. 117. 
conseguinte, não podem ser considerados um "mero nada". A necessidade dessas propriedades não é uma lei regulativa da operação representativa; ela é imposta ao pensamento pela necessidade da natureza da própria coisa pensada (AT, VII, "Meditationes", p. 67; AT, IX-1, "Méditations", p. 53). Por isso essas propriedades e os objetos que têm essas propriedades são no pensamento entes reais inteligíveis.

Embora restritas à essência dos objetos matemáticos, essas análises mostram que o ser objetivo tem uma realidade objetiva e daí um grau de perfeição: as propriedades que decorrem necessariamente desses objetos independem tanto da operação representativa quanto da realidade formal de coisas extensas que existem fora do pensamento. E como são consequências necessárias dos objetos dessas ideias, elas têm no pensamento uma natureza imutável, um grau de perfeição. Portanto, elas estão em mim, mas não são de mim, como assinalou H. Gouhier.

Não passou despercebida a Caterus a relação entre as noções de realidade objetiva e de essência. Para Caterus o que importa é mostrar que as ideias não são submetidas ao princípio causal. Mas ao menos uma razão (e não uma causa) tem que ser dada para o fato de que uma ideia tem esta e não aquela realidade objetiva. $\mathrm{O}$ que explica que um pensamento seja um pensamento de $\boldsymbol{x}$ e não de $\boldsymbol{y}$, de um homem e não de uma pedra, por exemplo? Caterus formula essa questão usando a expressão realidade objetiva: "Alguém talvez me dirá: se não dás uma causa para as ideias, dê ao menos uma razão pela qual esta ideia contém esta realidade objetiva ao invés de outra" (AT, VII, Primae Objectiones, p. 93; AT, IX-1, Premières Objections, pp. 74-75; grifo meu).

Uma interpretação tradicional da escola tomista tem uma resposta para essa pergunta: o conhecimento é uma assimilação de formas e a forma apreendida é uma forma intencional inteligível (que está no intelecto em razão de uma operação abstrativa) e é idêntica à forma que determina a essência das coisas. Quando se pensa em $\boldsymbol{x}$, pensa-se na forma intencional de $\boldsymbol{x}$ que especificou o ato de inteligir. Como a forma intencional de $\boldsymbol{x}$ é a mesma forma que a forma de $\boldsymbol{x}$, ao se pensar na forma intencional de $\boldsymbol{x}$, pensa-se na forma real de $\boldsymbol{x}$.

Caterus, ao responder a questão que formulou, generaliza para todas as ideias o que Descartes aplicara às ideias dos objetos matemáticos: as ideias representam essências (entes inteligíveis) e as essências apreendidas são eternas e verdadeiras. Ao pensar em $\boldsymbol{x}$ penso na essência de $\boldsymbol{x}$ que é diferente, por hipótese, da essência de $\boldsymbol{y}$. Com erudição e ironia, conclui Caterus, Davus é Davus e não é Édipo. Ora, as essências (eternas e verdadeiras), imagina 
Caterus, não precisam de causas. Assim, contra Descartes, Caterus teria mostrado que mesmo se a noção de realidade objetiva fosse assimilada à noção de essência, isto é, se a noção de realidade objetiva significasse entes inteligíveis (essências) no intelecto, as ideias, que exibem essências, não precisariam de causas, pois as essências são eternas. Ora, para Descartes, as essências são criadas e dependem somente da causalidade divina, ao contrário do que pensava a tradição medieval, ancorada em Scotus e em Suarez. ${ }^{27}$

A noção de essência, como se sabe, exerce um papel fundamental no argumento ontológico da $5^{\mathrm{a}}$ Meditação, ${ }^{28}$ assim como a noção de realidade objetiva exercera nas provas da existência de Deus da $3^{\text {a }}$ Meditação. Embora importante e com usos repetidos, são poucos os textos de Descartes, ao contrário da tradição medieval, que procuram caracterizar a noção de essência. Na Exposição Geométrica (AT, VII, Secundae Responsiones, Axioma 10; AT, IX-1, Premières Objections, Axioma 10) é afirmado ${ }^{29}$ que na ideia de cada coisa está contida uma existência possível ou necessária. Assim, a essência de uma coisa, representada por uma ideia, contém ou inclui uma existência possível ou necessária. A essência dos objetos matemáticos não precisa ser instanciada no mundo para ser considerada verdadeira e imutável. Ela contém apenas uma existência possível. Mas Descartes, além da expressão "essência verdadeira e imutável", usa também a expressão "essência inventada" ou "natureza fictícia ou composta pelo intelecto". ${ }^{30}$ Dessa maneira, ocorre implicitamente uma hierarquização das essências das coisas que são objetos das ideias; é preciso distinguir aquelas que contêm uma existência necessária das que contêm uma existência possível. E dentre as que contêm ou incluem uma existência possível, é preciso distinguir aquelas que são verdadeiras e imutáveis, das que são fabricadas ou compostas pelo intelecto.

27 Wells, 1990, pp. 33-61.

28 O subtítulo da 5a Meditação é "da essência das coisas materiais; e novamente de Deus, que Ele existe".

29 Nas Respostas às Primeiras Objeções, quer na edição latina, quer na versão francesa, algumas vezes esta tese é formulada de uma maneira diferente (AT, VII, Primae Responsiones, p. 116; AT, IX-1, Premières Réponses, p. 92): a existência possível está contida em tudo aquilo que nós concebemos clara e distintamente. No Axioma 10 da Exposição Geométrica não ocorre a expressão "clara e distintamente": em toda ideia ou conceito está contida a existência possível ou necessária. A condição clara e distintamente, expressa na Resposta às Primeiras Objeções, permite realçar a diferença entre as ideias dos objetos matemáticos e a ideia de Deus. A diferença entre elas não reside na clareza e na distinção dessas ideias, pois ambas são inatas, clara e distintamente percebidas. No entanto, as ideias dos objetos matemáticos contêm apenas uma existência possível, ao contrário da ideia de Deus, que contém uma existência necessária. Ver também AT, III, Carta a Mersenne, março de 1642, pp. 544-545.

30 Ver a ocorrência dessas expressões em AT, VII, Primae Responsiones, pp. 116-117; AT, IX-1, Premières Réponses, p. 92. Dessa maneira deve ser formulado um critério para distinguir as essências verdadeiras e imutáveis das inventadas pelo intelecto. Descartes procurou formular esse critério na sua resposta a Caterus. Sobre a natureza e a validade desse critério, ver nosso artigo "Argumento Ontológico" 2009, pp. 191-233, sobretudo pp. 206-214. 
A hierarquização das essências tem uma contrapartida na classificação cartesiana das ideias em inatas, factícias e adventícias (AT, VII, "Meditationes", pp. 37-38; AT IX-1, "Méditations", p. 29). Em carta endereçada a Mersenne, Descartes retoma a classificação formulada nas "Meditações" e acrescenta: "[...] eu distingui três tipos de ideias; [...] certas são adventícias [...] outras são fabricadas ou factícias, [...] outras inatas como a ideia de Deus, da mente, do corpo, do triângulo e em geral todas aquelas que representam quaisquer essências verdadeiras, imutáveis e eternas". ${ }^{31}$

Em outra carta $^{32}$ endereçada a um destinatário não identificado, analisando as distinções que reconhece como legítimas, Descartes retoma a questão da noção de essência. A essência pode ser considerada no pensamento de dois modos diferentes: seja fazendo abstração de que ela existe ou de que não existe, seja pensando-a como existente. Por exemplo, pensar em um triângulo e pensar em um triângulo existente. Do primeiro modo, pode-se distinguir essência de existência, pois se pode conceber algo que não existe atualmente, como seria o caso de pensar a rosa no inverno, como respondeu Descartes a uma pergunta de Burman. ${ }^{33}$ É a essência objetiva (essência pensada) que pode ser distinguida da existência, pois, do ponto de vista da existência efetiva, a coisa existente é a essência existente dessa coisa. ${ }^{34}$ Nesse caso, essência e existência não podem ser distinguidas. ${ }^{35}$ Finalmente, conclui Descartes: a essência objetiva (a essência pensada) se distingue realmente da essência existente: "Como também quando por essência inteligimos a coisa enquanto existe objetivamente no intelecto e por existência a mesma coisa enquanto existe fora do pensamento, é evidente que estas duas coisas são realmente distintas". ${ }^{36}$

Essas afirmações de Descartes realçam a tese de que uma mesma coisa (ou a essência de uma mesma coisa) pode ter um duplo modo de existência:

31 AT, III, Carta a Mersenne de 16 de junho de 1641, p. 383.

32 AT, IV, Carta a ${ }^{* * *}$, janeiro de 1645-46, pp. 348-350. Sobre a 'teoria' das distinções de Descartes, ver o texto canônico dos "Princípios da Filosofia" (Descartes, 2002, I, * 60-62) e a carta citada, que foi escrita depois da publicação da edição latina de 1644 dos "Princípios".

33 Descartes, 1981, p. 76.

34 AT, IV, Carta a ***, janeiro de 1645-46, p. 350: “[...] não ocorre a mesma coisa com o triângulo realmente existente fora do pensamento, quando me parece evidente que essência e existência não podem de nenhuma maneira ser distinguidas". Ver também Descartes (1981): "[...] a existência não é outra coisa senão a essência existente, [...]”, p. 79.

35 Note-se que a identificação entre essência e existência na coisa existente já está implicitamente afirmada na Resposta de Descartes a Caterus: "[...] a ideia do sol é o próprio sol existindo objetivamente no intelecto, certamente não formalmente, como no céu, mas objetivamente, isto é do modo pelo qual os objetos têm o costume de existir no intelecto [...]" AT, VII, Secundae Responsiones, p. 102; AT, IX-1, Premières Réponses, p. 82.

36 AT, IV, Carta $a^{\star \star *}$, janeiro de 1645-46, p. 350. 
uma existência objetiva no pensamento pela ideia e uma existência atual ou formal. Obviamente, sem outras considerações, não se pode deduzir da existência objetiva de uma coisa o seu correlato atual ou formal e vice-versa.

Se há um duplo modo de existência, qual seria o tipo de relação entre o ser objetivo de uma coisa e o seu ser formal? Essa questão é importante, pois, quer tenha ou não um correlato formal ou atual, o ser objetivo é o objeto visado e percebido pelo cognoscente, graças à operação representativa que o exibe. O que é imediatamente percebido é o ser objetivo. Se, como sugerem alguns textos de Descartes, ocorre uma relação de identidade entre o ser objetivo e o seu correlato formal, caso o correlato formal exista, ao se perceber o ser objetivo $\boldsymbol{x}$, ipso facto percebe-se $\boldsymbol{x}$ na sua realidade formal ou atual.

Descartes afirmou que pensar em um objeto (triângulo) e pensar sua existência (triângulo existente) são dois pensamentos que se distinguem modalmente. Em uma coisa efetivamente existente, a essência desta coisa não pode ser separada de sua existência, pois a existência da coisa é a essência existente da própria coisa. Mas, entre a essência objetiva de uma coisa e a existência atual fora do pensamento dessa coisa, ou entre a essência objetiva e a essência existente, há entre elas uma distinção real. ${ }^{37}$

Se o ser objetivo e o seu correlato forem realmente distintos, eles não podem ser numericamente idênticos, pois a identidade numérica não parece ser compatível com a distinção real entre dois entes. Como aplicar o princípio dos indiscerníveis, que caracteriza a identidade, ao ser objetivo e ao seu correlato formal, caso o correlato seja uma coisa extensa? A ideia do sol, por exemplo, não tem as propriedades da extensão e o sol na natureza não tem as propriedades do atributo pensamento. Ora, duas coisas numericamente idênticas satisfazem ao Princípio dos Indiscerníveis. Duas coisas realmente distintas (como, por exemplo, o sol e a ideia do sol) não satisfazem ao Princípio dos Indiscerníveis. Donde, duas coisas realmente distintas não são numericamente idênticas.

Dessa maneira, é implausível considerar que a relação entre o ser objetivo e o seu correlato extenso seja uma relação de identidade numérica. Talvez esta relação devesse ser interpretada como uma relação de similitude, pois as

37 Sobre essa questão, ver as observações de M. Ayers (1998, pp. 1067-68): "It seems clear that, at least on ordinary realist assumptions, there cannot be one thing, the idea, which is really identical, both to the mode of thought and to the real object." Ver D. Clemenson (2007, pp. 47-76). Neste livro, Clemenson procurou mostrar que dois entes com identidade numérica podem ser realmente distintos. Apesar da erudição do livro, seus argumentos sobre essa questão não me parecem convincentes. 
ideias, segundo a $3^{\mathrm{a}}$ Meditação, são "como imagens de coisas". ${ }^{38}$ Mas a ideia é uma representação na medida em que é considerada como uma operação cognitiva que exibe um objeto. Além disso, nos seus textos filosóficos, Descartes não analisou a noção de similitude, ${ }^{39}$ ao contrário, por exemplo, de Tomás de Aquino que inúmeras vezes usou este termo em sua obra e explicou o significado da expressão "similitude por representação". ${ }^{40}$ De fato, não seria uma tarefa fácil dar um sentido preciso à relação de similitude entre dois entes realmente distintos, tendo em vista que "similitude" é uma relação simétrica, ao contrario de "representação" que, na maioria dos casos, é uma relação assimétrica.

Mas há outra via para explicar a relação entre ser objetivo e o seu correlato formal, caso ele exista. $\mathrm{O}$ intelecto percebe imediatamente tudo o que nele ocorre. Ao perceber imediatamente, através de uma ideia inata, a realidade objetiva (ou essência) do ser objetivo, o intelecto apreende algo que não depende do pensamento humano, mesmo que não exista efetivamente 'fora' do pensamento. Mas quando apreende por uma ideia inata a essência de um ser objetivo e se esta essência existe efetivamente, ele apreende a mesma essência que está objetivamente no pensamento e que existe efetivamente fora do pensamento, caso a essência seja considerada sem os seus modos diferentes de existir. De fato, a essência do ser objetivo e a do seu correlato formal extenso são realmente distintas não em razão da sua natureza, que é a mesma, mas em razão dos seus modos de existir: no pensamento e na realidade efetiva. Assim, perceber um ser objetivo, mediante uma ideia inata, é perceber o que é a própria coisa, seja ela meramente possível ou atual.

Se $\boldsymbol{x}$ é um ser objetivo e tem um correlato formal $\boldsymbol{y}$, perceber $\boldsymbol{x}$, mediante uma ideia inata, equivale a perceber $\boldsymbol{y}$, pois ambos têm a mesma essência; $\boldsymbol{x}$ e $\boldsymbol{y}$ se distinguem realmente e não são, portanto, idênticos numericamente. Mas são distintos, não em razão das suas essências, que são idênticas quando

38 M. Gueroult é o mais notável intérprete cartesiano que defende a tese de que a ideia na sua realidade objetiva é um quadro. Ver, M. Gueroult, 1953, v. 1, pp. 140-141 e o capítulo 5, pp. 154-247. Contra essa interpretação de Gueroult, ver Wells, 1990, pp. 34-38, especialmente p. 36: "The 'image' in question is the cognitive activity of representing and not the "thing" represented."

39 M. Gueroult, 1953, p. 141: "D’où la nécessité de rechercher si ce que l'esprit voit dans le tableu correspond effectivement à la réalité de la chose. On pourrait, sans doute, se demander comment il se fait que l'esprit aperçoive le tableau comme une copie, comment est possible un tableau purement spirituel de ce qui exclut radicallement l'esprit. Mais ce sont là des questions que Descartes n'a jamais estimé devoir ni poser ni résoudre, vraisemblabement parce qu'elles dépassent selon lui les capacités de notre connaissance. Cette propriété de l'idée de représenter par la réalité objective la réalité formelle comme um tableau est le caractère constitutif qui nous permet immédiatement de la distinguer des autres pensées."

40 Ver "De Veritate", q. 2, a.3, ad 9 e q. 2, a. 5, ad 5 e ad 7. 
abstratamente consideradas, mas em razão dos seus modos de ser diferentes: objetivo e formal.

A percepção imediata do ser objetivo exibido por uma ideia ${ }^{41}$ acarreta a percepção imediata da essência do seu correlato formal, caso ele exista, pois como vimos, a essência representada por uma ideia inata é idêntica à do seu correlato formal, caso seja deixado de lado o modo de ser, objetivo ou formal, da essência. Dessa maneira, o ente objetivo não é um intermediário, um tertium quid, entre o sujeito cognoscente e a própria coisa. Assim, a tese do acesso direto às coisas mesmas não é incompatível com a tese do 'acesso' imediato ao ser objetivo. Sob este aspecto, a teoria cartesiana é uma forma de Realismo Direto.

No entanto, é preciso distinguir a questão da percepção da essência de uma coisa externa da questão da prova da existência de coisas.

Os entes objetivos são entes reais no pensamento. Nesse sentido, como tudo o que é real, eles são também submetidos ao princípio causal (AT, VII, "Meditationes", p. 42; AT, IX-1, "Méditations", pp. 32-33). Mas, em princípio, uma ideia pode ser causa de outras ideias (AT VII, "Meditationes", pp. 43-45; AT, IX-1, "Méditations", pp. 34-35). Esse nexo causal entre as ideias não pode se prolongar ao infinito, afirma Descartes (AT, VII, "Meditationes", p. 42; AT, IX-1, "Méditations", p. 33). É preciso chegar a uma ideia cuja realidade objetiva tenha como causa uma realidade formal, que contenha, ao menos, tanta perfeição formal quanto a perfeição objetiva da ideia, pois é da natureza das ideias, ao menos as primeiras e originais, terem como causa uma realidade formal. ${ }^{42}$

As provas da existência de Deus na $3^{\text {a }}$ Meditação usam o princípio de causalidade aplicado à realidade objetiva das ideias. Na 6 a Meditação, a prova da existência dos corpos é também uma prova inferencial de existência. No entanto, tendo em vista a indeterminação do grau de realidade objetiva das ideias sensíveis, não é possível inferir da sua questionável realidade objetiva a realidade formal da coisa. ${ }^{43} \mathrm{O}$ ponto de partida da prova da existência dos corpos

41 AT, VII, Objectiones Tertiae, Objectio V, Responsio: "[...] eu tomo pelo nome de ideia tudo o que é imediatamente concebido pela mente" (AT, IX-1, Troisièmes Objections, Objectio V, Réponse). Ver também AT, VII, Secundae Responsiones, Def. I e II; AT, IX-1, Secondes Réponses, Def. I e II; grifo meu.

42 Ver Beyssade, 1997, pp. 46-48.

43 É interessante notar que na Exposição Geométrica (Descartes. Obra Escolhida, "Respostas às Segundas Objeções", Axioma V), Descartes supõe implicitamente que as ideias sensíveis têm realidade objetiva. "E cumpre notar que este axioma deve ser tão necessariamente admitido que só dele depende o conhecimento de todas as coisas sensíveis como insensíveis Pois, como sabemos, por exemplo, que o céu existe? Será porque o vemos? Mas essa visão não afeta de modo algum o espírito, a não ser na medida em que há uma ideia: uma ideia, digo, inerente ao próprio espírito, e não uma imagem pintada na fantasia; e, por ocasião dessa ideia não podemos julgar que o céu existe, a não ser que suponhamos que toda 
é a consciência da receptividade e da coerção que caracterizam a consciência sensível. ${ }^{44}$ Após uma sequência de argumentos que envolvem outras premissas e teses, dentre as quais a tese da distinção real entre o pensamento e a extensão e a tese da Veracidade Divina, o princípio de causalidade é usado para provar que algo exterior ao sujeito pensante (e de natureza diferente dele, em razão da distinção real), os corpos extensos, são causas das ideias sensíveis e, portanto, existem. Sob este aspecto, a teoria cartesiana poderia ser interpretada como um Representacionalismo inferencial, pois as provas de existência da $3^{\mathrm{a}}$ Meditação e a prova das coisas extensas, usando o princípio de causalidade, inferem a partir de dados imanentes do pensamento a existência de realidades formais atuais.

Mas nem todas as provas de existência das "Meditações" são inferenciais: nem o Cogito nem o Argumento Ontológico recorrem, por exemplo, ao Princípio de Causalidade. Assim, o Representacionalismo realista cartesiano está restrito nas "Meditações" a algumas provas de existência: a da existência de Deus, formulada no contexto cético da $3^{\mathrm{a}}$ Meditação, e à prova da existência dos corpos extensos.

$\mathrm{Na}$ teoria cartesiana, as interpretações Realista Direta e Representacionalista inferencial, aplicadas a questões distintas, convivem harmonicamente. $\mathrm{O}$ reconhecimento de dois modos de existência, objetivo e formal, são distinções conhecidas e assumidas pelos medievais. Mas a superação do ceticismo e a prova da existência de coisas extensas, graças ao princípio de causalidade, tendo como ponto de partida os dados intencionais e imanentes ao intelecto parece ser uma contribuição original e decisiva da filosofia primeira de Descartes.

\section{Referências}

\section{[A] Descartes}

ADAM, C., TANNERY, P. “Euvres de Descartes”. Paris: Vrin-CNRS, 1964-1974. $11 \mathrm{Vol}$.

DESCARTES, R. “L' entretien avec Burman”. Edição, tradução e anotação de J.-M. Beyssade. Paris: PUF, 1981.

. "Obra escolhida". Tradução de J. Guinsburg e Bento Prado Júnior. São Paulo:

Difusão Européia do Livro, 1962.

ideia deve ter uma causa de sua realidade objetiva que seja realmente existente; causa que julgamos ser o céu mesmo; e assim por diante" (grifo meu). Ver também AT, VII, Secundae Responsiones, p. 135; AT, IX-1, Secondes Réponses, p. 107.

44 Landim, 2009, pp. 261-267. 
. "Princípios da Filosofia". Edição bilíngue, tradução e organização de Guido Antônio de Almeida e outros. Rio de Janeiro: UFRJ, 2002.

\section{[B] Bibliografia secundária}

AQUINO, T. "Quaestiones Disputatae de Veritate". In: Opera Omnia. Tomo XXII, Vol. 1-3. Ed. Leonina. Roma: Ed. di San Tommaso, 1970-1976.

ARNAULD, A. "Des vraies et des fausses idées". Edição Corpus des Euvres de Philosophie en Langue Française. Paris: Fayard, 1986.

AYERS, M. "Ideas and Objective Being". In: The Cambridge History of Seventeenth Century Philosophy. Cambridge: Cambridge University Press, 1998. 2 Vol.

BEYSSADE, M. "A dupla imperfeição da ideia segundo Descartes”. Analytica, Nr. 2, 1997.

BROWN, D. “Objective Being in Descartes”. In: H. Lagerlund (ed.). Representation and Objects in Medieval Philosophy. Burlington: Ashgate Publishing Company, 2007. CHAPPELL, V. "The Theory of Ideas". In: A. Rorty (ed.). Essays On Descartes" Meditations. Berkeley: University of California Press, 1986.

CLEMENSON, D. "Descartes' Theories of Ideas: Continuum Studies in Philosophy". Londres: Continuum International Publishing Company, 2007.

COULOUBARITSIS; MAZZÙ, A. (ed.). “Questions sur l' Intentionalité”. Bruxelles: Ousia, 2007.

DALBIEZ, R. "Les sources scolastiques de la théorie cartésienne de l'être objectif". Révue d'Histoire de Philosophie, $3^{\mathrm{eme}}$ année, Fasc. 4, oct./déc. 1929.

EUSTACHIO À SANCTO PAULO. "Summa Philosophica Quadripartita de Rebus Dialecticis, Moralibus, Physicis et Metaphysicis". Quarta Pars, De communitate entis deque eius convenientia cum inferioribus membris. Paris: Carolus Chastellain, 1609. 2 Vol.

GARBER, D., AYERS. M. (ed.). "The Cambridge History of Seventeenth Century Philosophy". Cambridge: Cambridge University Press, 1998. 2 Vol.

GOUHIER, H. "La Pensée Métaphysique de Descartes". Paris: Vrin, 1987.

GUEROULT, M. “Descartes selon L'Ordre des Raisons”. Paris: Aubier, 1953. 2 Vol. HOFFMAN, P. "Direct Realism, Intentionality and the Objective Being of Ideas". Pacific Philosophical Quartely, Nr. 83, 2002.

KEMMERLING, A. "As It Were Pictures. On the Two-Faced Nature of Cartesian Ideas". In: Perception and Reality: From Descartes to the Present. Padeborn: Mentis, 2004.

SCUMACHER, R. (ed.). "Perception and Reality: From Descartes to the Present". Padeborn: Mentis, 2004.

LAGERLUND, H. (ed.). "Representation and Objects in Medieval Philosophy". Burlington: Ashgate Publishing Company, 2006.

LANDIM FILHO, R. "Argumento ontológico: a prova A priori da existência de Deus na Filosofia Primeira de Descartes". In: R. Landim Filho. Questões disputadas de metafísica e de crítica do conhecimento. São Paulo: Discurso Editorial, 2009. 
. "Idealismo ou Realismo na Filosofia Primeira de Descartes". In: Questões disputadas de metafísica e de crítica do conhecimento. São Paulo: Discurso Editorial, 2009.

"Questões disputadas de metafísica e de crítica do conhecimento". São Paulo: Discurso Editorial, 2009.

MICHON, C. "L'Éspece et le Verbe”. In: Couloubaritsis, A. Mazzù (ed.). Questions sur l'Intentionalité. Bruxelles: Ousia, 2007.

NADLER, S. "Arnauld and the Cartesian Philosophy of Ideas". Princeton: Princeton University Press, 1989.

NORMORE, C. "Meaning and Objective Being: Descartes and his Sources". In: A. Rorty (ed.). Essays on Descartes' Meditations. Berkeley: University of California Press, 1986.

ONG-VAN-KUNG. "L' Objet de nos Pensées: Descartes et l' Intentionalité". Paris: Vrin, 2012.

PERLER, D. (ed.). “Ancient Theories of Intentionality”. Leiden: Brill, 2001.

PERLER, D. "What are Intentional Objects: a Controversy among early Scotists". In:

D. Perler (ed.). Ancient Theories of Intentionality. Leiden: Brill, 2001.

RORTY, A. (ed.). "Essays on Descartes' Meditations". Berkeley: University of California Press, 1986.

THOMAE DE VIO CAIETANI. "Commentarium super Opusculum De Ente et Essentia Thomae Aquinatis”. Roma: Ex Pontificia Officina Typographica, 1907. c. IV, q. 7.

TWEEDALE, M. "Representation in Scholastic Epistemology". In: H. Lagerlund (ed.). Representation and Objects in Medieval Philosophy. Burlington: Ashgate Publishing Company, 2006.

WELLS, N. "Objective Reality of Ideas in Descartes, Caterus and Suarez". Journal of History of Philosophy, Vol. 28, Nr. 1, Jan. 1990.

"Descartes Ideas and its Source". American Catholic Philosophical

Quartely, Nr. 4 [dedicado a Descartes], Autumn 1993. 